\title{
Further Democratizing Latin America: Broadening Access to Higher Education and Promoting Science Policies Focused on the Advanced Training of Human Resources
}

\author{
Manuel Heitor', Hugo Horta²
}

\begin{abstract}
We focus this paper on the conditions to build reliable science, technology and higher education systems in Latin America, based on international comparative studies, fieldwork and interviews conducted over the last three years. The analysis shows that science can have a major role in furthering the democratization of society through public policies that foster opportunities to access knowledge and the advanced training of human resources. Broadening the social basis for higher education promotes the qualification of the labour force and contributes decisively to social and economic development. The need to guarantee higher education diversity, strengthening scientific institutions and investing in a strong science base, is deemed as critical, but goes far beyond policies centred on innovation and industry-science relationships. It requires adequate training and attraction of skilled people, as well as promoting scientific and technological culture among society.
\end{abstract}

Keywords: open access to science and higher education; higher education diversity; education equality; strengthening the science base; science and democracy; latin america

\footnotetext{
1,2 Center for Innovation, Technology and Policy Research, IN+. Instituto Superior Tecnico, University of Lisbon, Portugal, e-mail: mheitor@ist.utl.pt.

${ }^{2}$ The University of Hong Kong, Hong Kong SAR, China, e-mail: hugo.horta@ist.utl.pt
} 


\section{Introduction}

This paper contributes to reflect on the role science and higher education policies, if adequately integrated, may play in Latin America by underlining their relevance in further democratizing and promoting social-economic development through two complementary goals in association with: i) opening access to the knowledge base through higher education; and ii) promoting advanced qualification of skilled people and strengthening research institutions through adequate consideration of human resources and institutional issues in technical change. This requires a better understanding of diversity in higher education, as well as of the effective role played by science-university relationships, beyond the most "common places" and currently dominating policies of thinking science through short-term, demanddriven economic development issues (Heitor, 2008; Heitor and Bravo, 2010). The rational for our approach is related to the need of promoting a sufficient $y$ stable environment to train and supply talented people, including researchers for knowledge intensive, fast-paced, and uncertain labour markets. This gains particular relevance vis a vis the growing demand of higher education by populations perceiving private and social returns of education (Altbach et al., 2009).

In responding to the explosive social demand for higher education and to vast social and political transformations already induced by new waves of educated youth, countries face the need and the opportunity for large investments in science, technology and higher education (Roberts and Hite, 2007). This is a fundamental matter for Latin America since unbalances in educational level, and in the enlargement of the highly qualified human pool have been a long identified issue for their sustained social-economic development (Carlson, 2002).
For most Latin American countries and regions the main challenges are threefold. First, to broaden the access to higher education; second, to make this access more socially balanced (see, for example, Kohli, 2009); and, third, to recover from a long gap in investing in the knowledge base, as quantified by the level of investment in R\&D and its gap in relation to current levels of industrialized countries. For example, Brazil's gross enrolment ratio in higher education was $29 \%$ in 2012 and the percentage of the population aged 25-64 years old that has attained tertiary education was below $12 \%$ in $201 \mathrm{I}$, Figure I. Although the country is far away from a "massified" higher education system, the current figu es are well above the level of gross enrolment ratio defined by Martin Trow (2007) for typical "elitists" higher education systems (i.e., about 15\%). A similar trend is observed in other Latin American countries, including El Salvador (25\%) or Mexico $(29 \%)$, and to a lesser extent in Paraguay (35\%) and Peru (43\%). On the other hand, Puerto Rico (86\%), Argentina (79\%), and Chile (74\%) [data from UNESCO for 2012 or the last available year; Data from Brazil refers to the National higher education census of 2013] have tackled this issue and are evolving towards "universal" higher education system, with enrolment rates well above $60 \%$. Nevertheless, the percentage of the population aged 25-64 years old that has attained tertiary education in $201 \mathrm{I}$ was below $14 \%$ in Argentina, Figure I. With the notable exception of Chile (as it is characterized by relative qualification levels similar to France and Germany), all other Latin America countries still rely in low-skilled active populations, sharing with the Mediterranean basin countries the challenge to further qualify their population (Giordano and Pagano, 20I3).

Regarding the challenge of making access to education more socially balanced, Figure 2 shows that the majority of students enrolled in higher education in Latin American countries are still mostly from those families with the highest income. In Chile - a country with a universal higher education system - $62 \%$ of the highest income quartile population in tertiary education age are enrolled in higher education against only $21 \%$ of those from the lowest income quartile. In Brazil, about $47 \%$ of the highest income quartile population in tertiary education age are enrolled in higher education, while only $5 \%$ of the lowest income quartile population is enrolled in tertiary education. The data clearly shows that social unbalance in higher education access is affecting Latin America in different stages of higher education development and maturity. This needs to be tackled in order to meet globally accepted equity standards towards sustainable societies, where broad access to education potentiates the formation of highly trained labour forces and their contribution to social and economic development. 


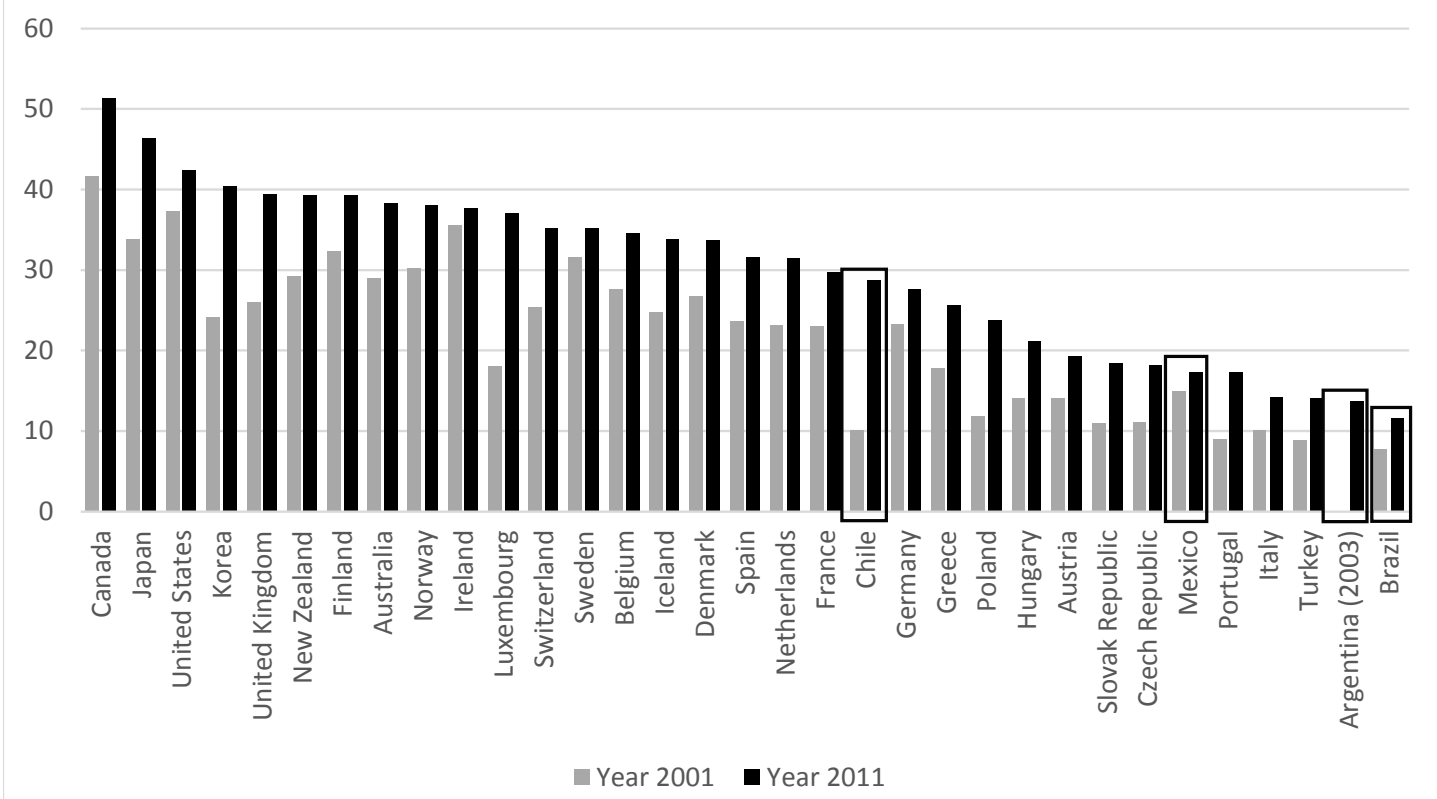

Figure I. Percentage of the population (aged 25-64 years old) that has attained tertiary education, 20I0/20I I or latest available year; Source: UNESCO, OECD, IBGE, CNPQ

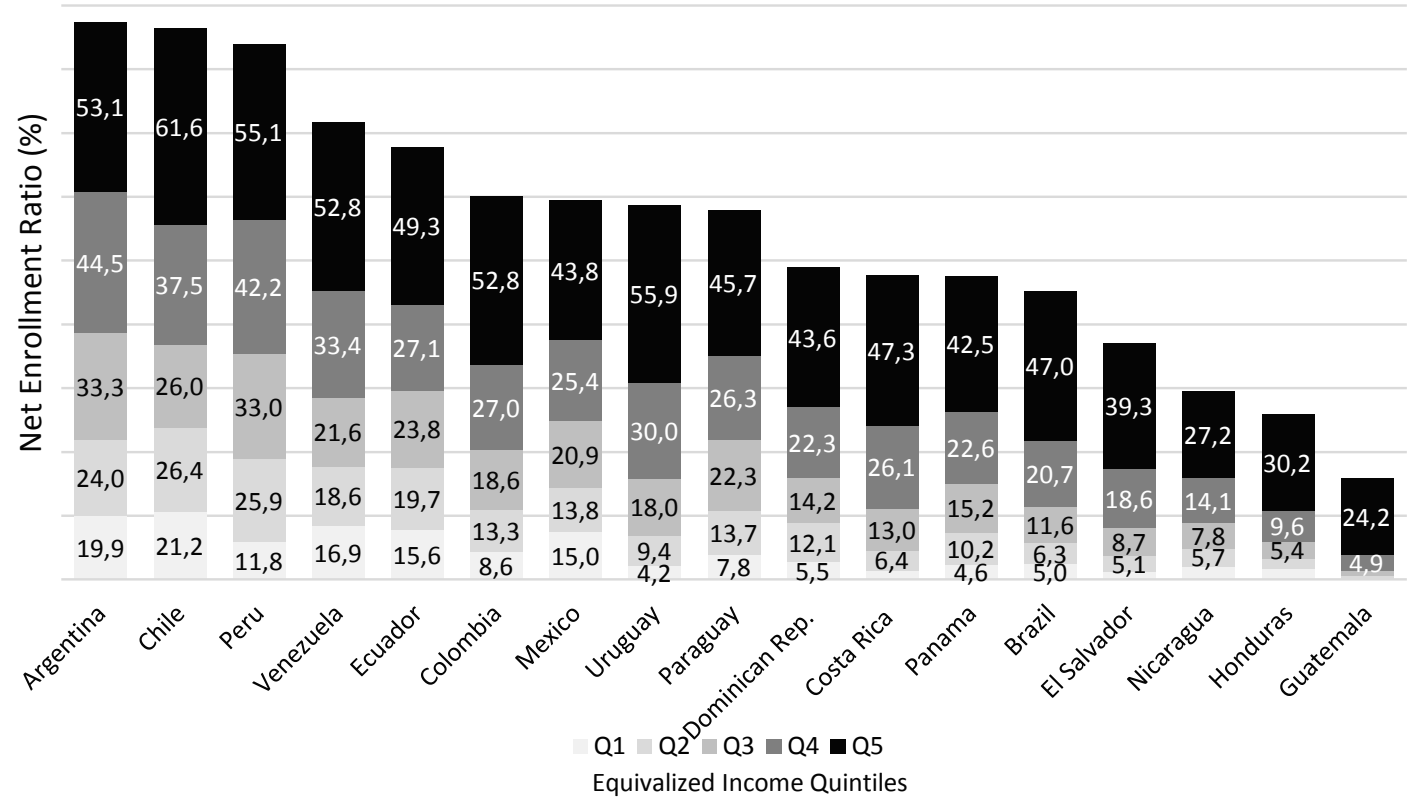

Figure 2. Net enrollment rates on tertiary education by income quintiles, 2012 or latest available Source: SEDLAC (Socio-Economic Database for Latin America and the Caribbean) - Universidad Nacional de la Plata and the World Bank. 
Finally, increasing the investment in science and technology in Latin America is becoming critical to facilitate the conditions to nurture knowledge intensive environments where researchers and academics can be trained and develop knowledge based activities, Figure 3. South American R\&D remains relatively small (Batelle, 20I3), albeit with some noteworthy national initiatives. For example, gross expenditure in R\&D in Brazil has not been able to surpass $1.3 \%$ of GDP, and in Argentina it is kept as low as $0.6 \%$. Overall, the region lags in R\&D capacity-even Brazil appears to be under-performing expectations.

Taking this context into account, the building-up of knowledge institutions together with higher education assumes critical relevance in Latin America. But, how to frame adequately integrated higher education and science policies to foster this process? This question has driven the research behind this paper, which emphasizes the way public policy can open new opportunities for modernizing higher education systems in Latin America for the years to come, as well as improve access to higher education and better qualify the labour force. In this framework, international references are used wherever appropriate to facilitate the discussion of lessons learned from elsewhere, in a scope that strengthens the message of Nowotny et al. (2003) that "science is contextualized". The dynamic relationship between society and knowledge production is explored, considering the social construction of knowledge-based systems (Bijker et al., 1987), together with the need to consider "inclusive learning" (Conceição and Heitor, 2002).

\section{Research Framework and Analysis}

In the following paragraphs we present and discuss our main findings about higher education systems and related public policies in Latin America. Our analysis draws from international comparative studies, field ork and interviews conducted over the last three years, in addition to our selfexperience as researchers and policymakers in the field of science and higher education policy. On-site visits and many discussions with researchers and policymakers were carried out with special emphasis on Brazil (Rio de Janeiro, São Paulo, Brasilia, Rio Grande do Sul, Fortaleza), Colombia (Bogota, Medellin, Cartagena), Argentina (Buenos Aires) and Chile (Santiago), addressing challenges for higher education and science policies. The work involved participation in a Policy Research Worksop organized by the World Bank, the OCDE and BNDES in Rio de Janeiro (October 20II), a

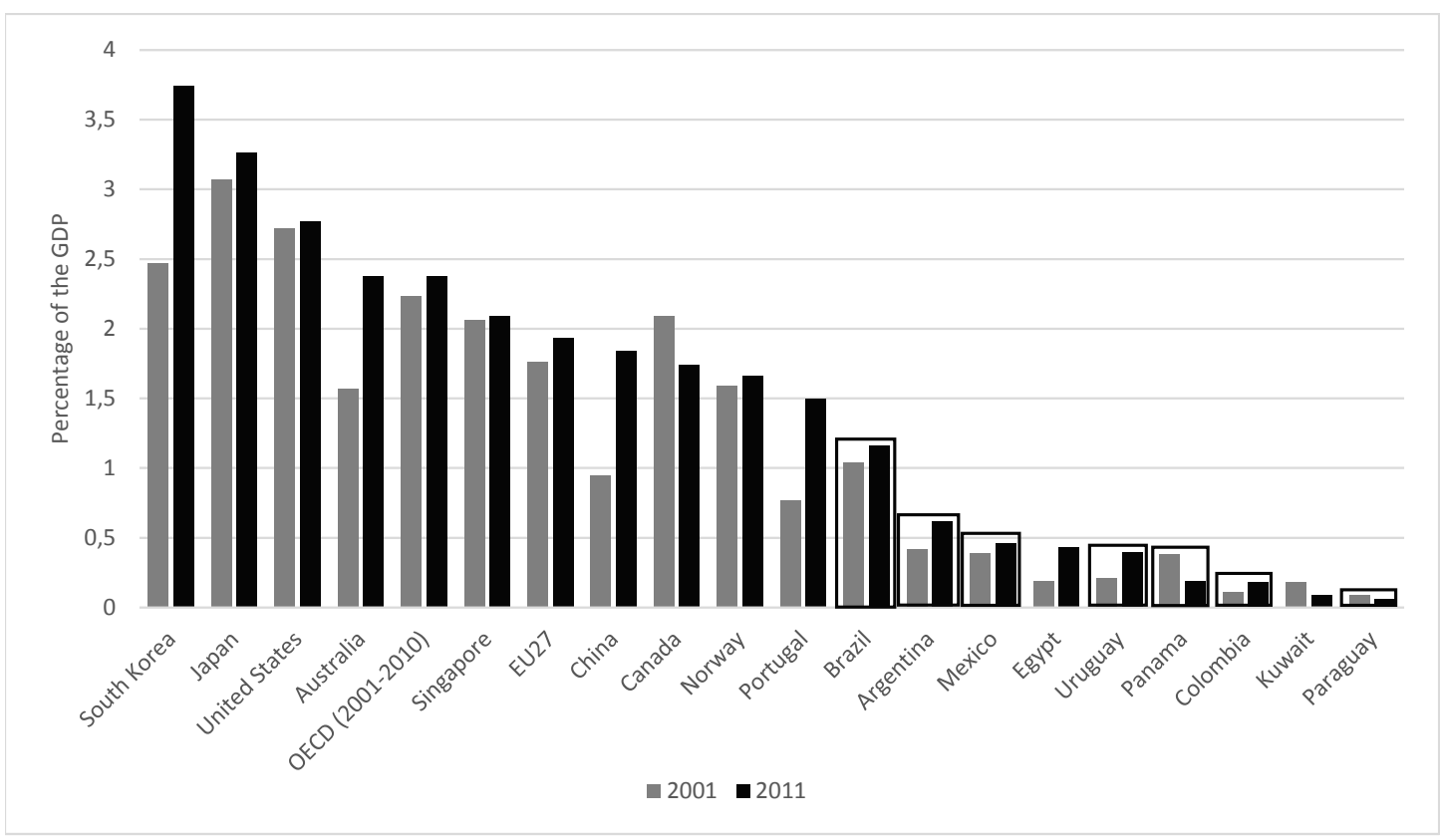

Figure 3. Gross Expenditure on R\&D as a percentage of GDP, selected countries, $200 \mathrm{I}$ and $20 \mathrm{II}$

ISSN: 07 I8-2724. (http://www.jotmi.org)

Journal of Technology Management \& Innovation (c) Universidad Alberto Hurtado, Facultad de Economía y Negocios. 
School of Advanced Studies at the Federal University of Rio de Janeiro (UFRJ, March 20I3), two Research Workshops in Fortaleza, Ceará (September 2012 and December 20I3) and an Education and Innovation Summit in Bogota (May 2014). A major event and Research Workshop was organized in Porto, Portugal, in October 2013 bringing together over 800 experts in science, technology and innovation policies in Latin America (ALTEC 2013, http://www.altec2013.org/ ). The analysis have underlined the need to better consider the process of developing human capital, as well as the role that higher education and scientific institutions have to facilitate it. Human capital is vital for the creation and dissemination of knowledge (Lall, 1990), and striving towards greater human capital is of the utmost importance for both developed and developing countries, with a special emphasis for Latin America. This ultimate goal requires, per si, policies and strategies towards effective institutional autonomy and integrity of modern universities in a context where alliances and partnerships among universities worldwide, as well as between them and corporations, gain significant relevance. Our analysis worldwide shows that universities need to be both adaptable and resilient and this requires policies towards effective institutional autonomy and integrity of higher education institutions. It also highlights the need to give constant priority to people and knowledge in a way that provides networks of institutions with the necessary critical mass capable of promoting the international standing of scientific and higher education institutions. Two further issues should be emphasized.

First, innovation must be considered together with competence building and advanced training in individual skills through the complex interactions between formal and informal qualifications (Helpman, 2004). This requires broadening the social basis for knowledge activities, including higher education enrolment, and strengthening the top of the research system leading to knowledge production at the highest level. Figure 4 underlines the importance of having critical mass of researchers to create and reshape knowledge. The most developed regions of the world have high rates of researchers per 1000 labour force, and are striving to increase even more those rates (see the case of the OECD countries and Europe).With the exception of Russia, all the other regions are striving to attract and accumulate talented people, but it should be clearly stated that all Latin America regions are still characterized by very low concentrations of "knowledge workers", at least when measured in terms of the number of researchers per thousand labor force, Figure 4. For example, the number of researchers per thousand labour force in Finland in $201 \mathrm{I}$ was 5 times greater than that of Argentina, the Latin American country with most researchers per thousand labour force.

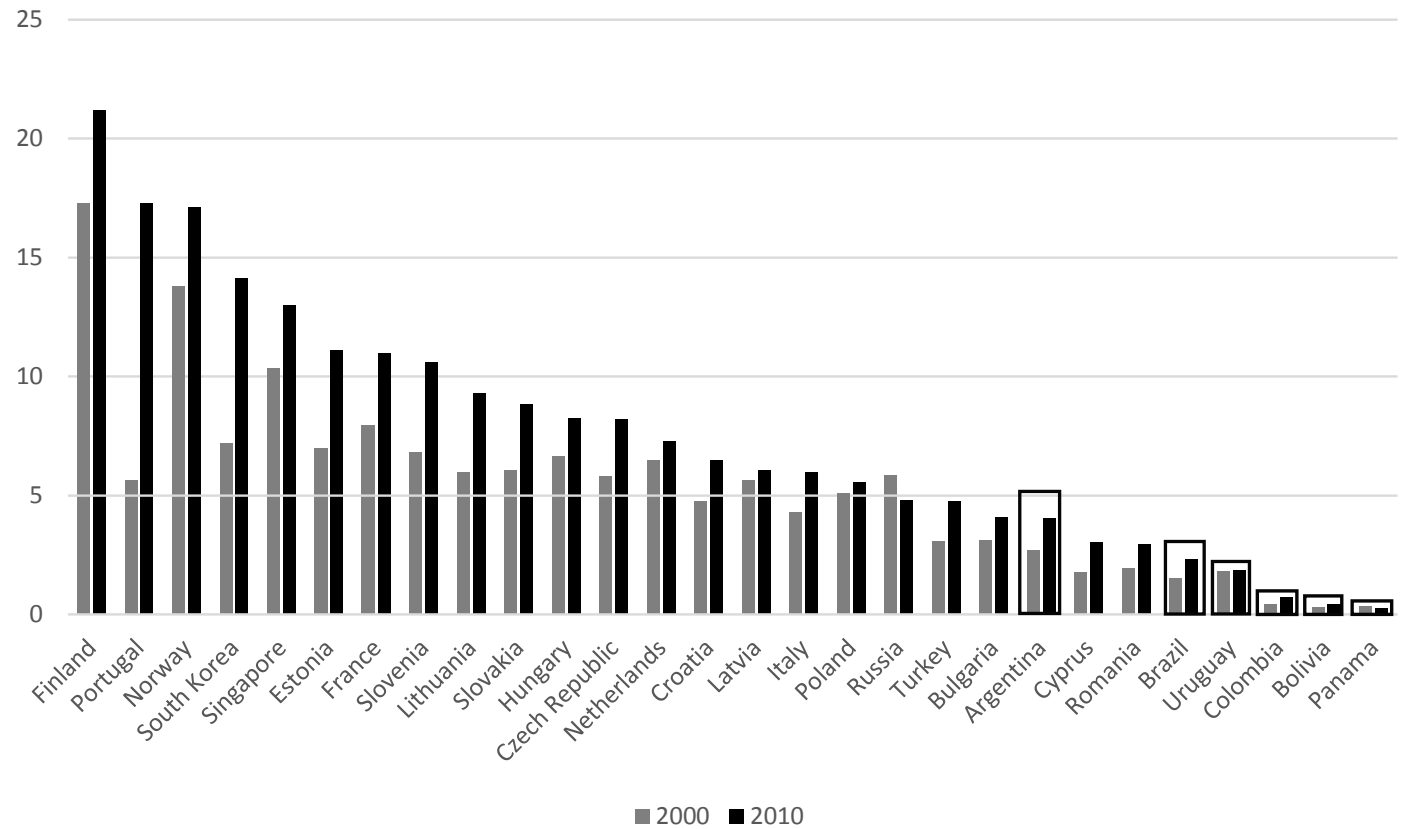

Figure 4. Total number of researchers (head count) per thousand-labor force, 2010/20II or latest available year; Source: UNESCO, OECD, IBGE, CNPQ

ISSN: 07 I8-2724. (http://www.jotmi.org)

Journal of Technology Management \& Innovation (c) Universidad Alberto Hurtado, Facultad de Economía y Negocios. 
Second, strengthening experimentation in social networks necessarily involves $\mathrm{fl}$ ws of people, independently of their socio-economic level. It is the organized cooperation among networks of knowledge workers, together with different arrays of users across the entire social fabric of our societies that will help diffuse innovation and the design of products and services (Ernst and Kim, 2002). But establishing these innovation communities requires the systematic development of routines of collaboration on the basis of formal education programs, research projects, and a diversified and non-structured array of informal processes of networking (see Saxenian, 2006; Tung, 2008). Figure 5 shows that the entire Latin America still relies in comparatively low Education Equity Indexes, EEI, at an international level. For example, Brazil's EEI in 2008 was still below $12 \%$ and the entire Latin America about 23\%, corresponding to about half of the average value for all countries considered in the statistical sample.
The analysis drives us to consider, in detail, the key policy issues associated with the penetration of higher education in Latin America. First, the most important contextual change, shared by all emerging regions and countries in Latin America, is the rapid expansion of the higher education sector associated with social and economic aspirations. Second, along with an expanding demand, there is a need for greater diversity of provision, in order to better address diversified "publics" across a quite diversified socio-economic societal background. Third, competition among emerging regions is becoming intense, with the realization that quality higher education and research, and its permeability in the economy, holds critical steps towards economic growth. Fourth, pressures for change are also coming from national and local governments towards more responsive institutions associated to new public management approaches and steering models.

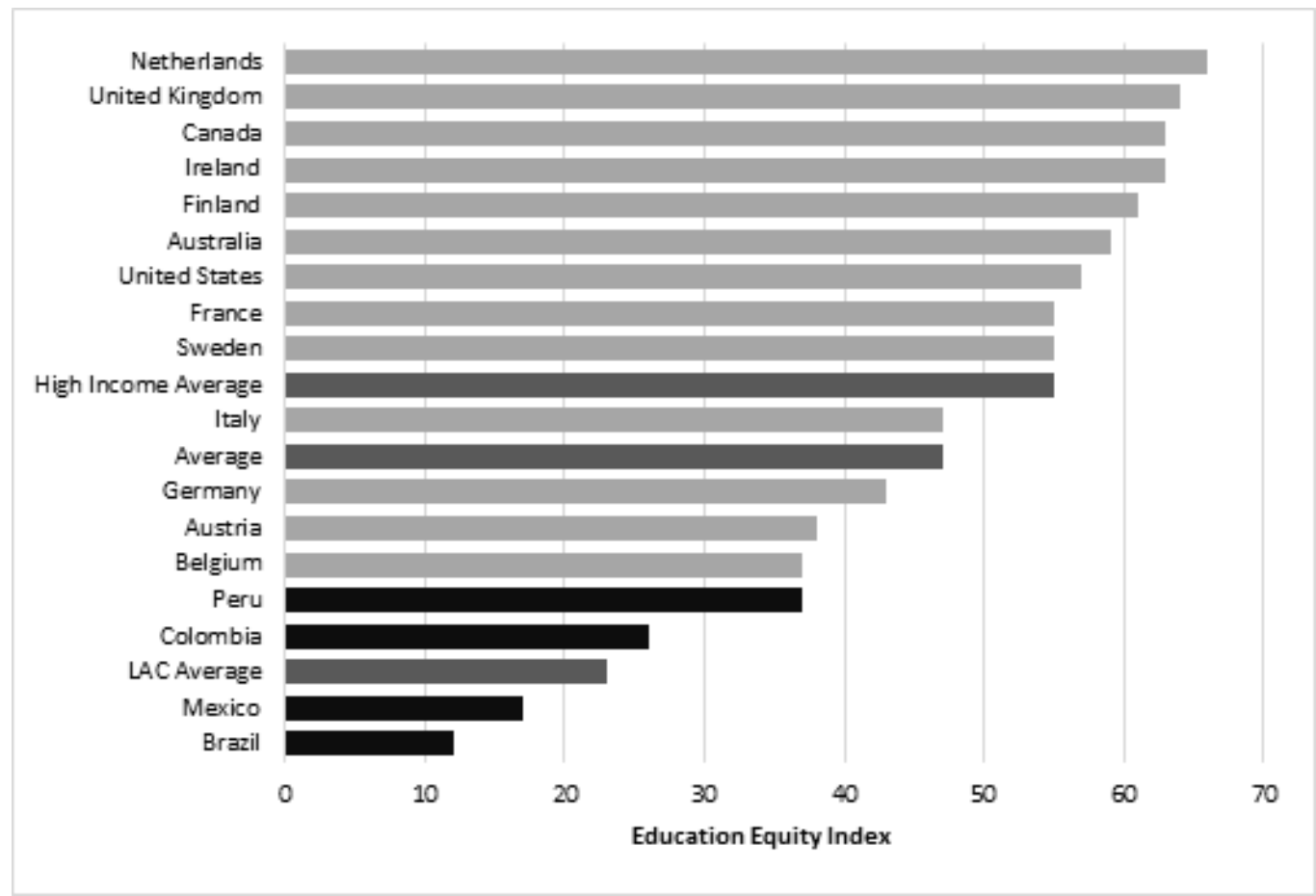

Figure 5. Education Equity Index, EEl, last year available, or 2008.

Source: SEDLAC (Socio-Economic Database for Latin America and the Caribbean) - Universidad Nacional de la Plata and the World Bank.

ISSN: 07 I8-2724. (http://www.jotmi.org) 


\section{The research hypothesis: further diversifying higher education in Latin America}

The analysis reported above suggests that higher education institutions in Latin America (and elsewhere) are increasingly pressed to respond to the needs of society, including to unforeseeable changes in employment markets. This includes expanding their operations and preparing their graduates with learning skills beyond merely technical competences (see Werfhorst, 20I4). Yet, higher education institutions cannot be expected to foresee the demands of the employment market in advance (not even firms are able to do it). Our hypothesis is that this can be addressed by further developing a diversified higher education system, encompassing various institutions with different vocations, together with policies and a regulatory framework towards their increasingly diversification (Teichler, 2008). In many parts of the world this issue has been addressed by strengthening the role of scientific research, together with master and doctorate formal education, in universities, while focusing on problem-oriented research, together with short cycles of professional and vocational formal education, in non-university higher education institutions (i.e., "Community Colleges" in US, "Fachhochschulen" in Germany and Swiss, "Hogeschools" in The Netherlands, "Polytechnics" in Portugal). In addition "distance learning" can also facilitate this process, as discussed below.

The literature on diversity of higher education shows that fostering structural diversification of higher education systems has occurred either by creating dual system institutions (internal diversity) or through a binary model (referring to systemic diversity that most European countries adopted; Horta et al., 2008). The latter creates an institutional differentiation of higher education, with university institutional missions mostly associated with undertaking research and postgraduate education, while providing a general education to undergraduates. On the other hand, non-university higher education institutions focuses mostly on short term learning cycles and vocational and professional training (Teixeira et al., 20I2). The main challenge worldwide has been associated with the need to foster the social acceptability and technical credibility of both type of institutions. Our analysis shows that this requires adequate and diversified science policies, creating and promoting incentives for all institutions and, simultaneously, differentiating the type of research at universities and nonuniversity higher education.
This is because non-university higher education institutions are expected to be regionally focused and position themselves near to the labour markets, with fast responses to changes in the demand for qualified people. This requires they develop institutional abilities to identify the needs of local employment trends and promote regional clusters of innovation. At a large extent, this issue remains to be entirely solved, although their role to foster qualifications across the entire social fabric is undeniable, including the access of adult students to higher education, by removing barriers to their entrance and success (Saar et al., 2014; Koljatic and Silva, 2013).

The analysis reinforces the need to open and strengthen diversified systems of higher education in Latin America, allowing for different learning and teaching frameworks in professionally oriented and academic-driven programs. Only a diversified higher education system can cope with a growing diversity of students' characteristics, learning demands, and societal needs (Werfhorst, 2014; Boliver, 20II). Diversified higher education systems could also ensure sustained adaptation, and flexibilit, capable of providing society with the instruments it needs to deal with instability in employment and, more generally, the inevitable changes in technology, trends, markets and needs. This seems moreover to be the way to meet the challenge of maintaining excellence, together with the required massification of education systems.

Our analysis about institutional diversification and specialization in Latin America also encompasses the emerging role "distance learning" may play. We prefer to use "distance learning" (DL), as opposed to "distance education" (DE) in order to emphasize the centrality of learners in the teaching and learning process. In addition, it is also important to clarify that the "distance" component of DL is a continuum that ranges from a largely face-to-face or "presential" mode of delivery to a largely distance delivery mode. For example, distance-learning students interact with tutors in face-to-face situations or undergo assessments under supervision. Hence, the use of on-line systems does not mean that it is a full DL system of provision because the on-line systems could be used simply to support face-toface mode of provision.

The international experience with $D L$ shows two dominant trends. First, from the paper-based classical pedagogy, DL has moved to virtual and interactive teaching and learning processes, which represent a dramatic shift from the dimension of "space" in distance learning to the dimension of "time". Second, the use of the blended models by traditional universities, which uses the new DL pedagogy in support of classical face-to-face instruction has spread rapidly and represents the wave of the future. 
A leading example worldwide is that of Brazil, where DL has been successfully attained through Universidade Aberta do Brasil (UAB) and CEDERJ in Rio de Janeiro. UAB is a publicly funded joint program of Brazil's Ministry of Education with the State and Municipalities, with a co-operative offer by 70 public higher education institutions, now has more than 100,000 students in undergraduate and graduate programmes. These institutions share some 550 learning centres distributed all over Brazil and several other facilities, like materials production and delivery, internet facilities, training in DL for professors, tutors and technical staff, among others. The learning centres and the infrastructure are partially provided by the State and Municipal governments.

CEDERJ is a consortium composed of six public universities, offering nine programs for more than twenty thousand students, with 33 learning centres distributed in the State of Rio de Janeiro. The disciplines in one particular program are shared among the universities. To support these activities a State Foundation, CECIERJ, was created with a specific budget, which produces the materials with the professors of the universities, administers the DL process, the learning centres, the platform, the teaching and the DL tutorial systems.

A major argument for $\mathrm{DL}$ as a tool for promoting higher education is its lower marginal cost per student compared with face-to-face instruction. On this logic, expansion of $D L$ could be achieved with comparatively smaller investment (Larson and Murray, 2008), albeit setting up DL programmes requires large initial investments, which can pay-off in lower marginal costs per student after several years and with high levels of student intake.

\section{A main challenge: framing the advanced training of human resources and teaching staff}

Goldin and Katz (2008) claim that the last century was both the American Century and the Human Capital Century, by no accident. The connection between the two titles concerns the role of education in economic growth and individual productivity. A greater level of education results in higher labor productivity. Moreover, a greater level of education in an entire nation tends to foster a higher rate of aggregate growth. The authors claim that the nation that invested the most in education, and did much of that investment during the century, in which education would critically matter, was the nation that had the highest level of per capita income.

Recently, Phelps (2013) argues that prosperity explode in some nations between the 1820 s and 1960 s, creating not just unprecedented material wealth, but "flourishing" meaningful work, self-expression, and personal growth for more people than ever before. Phelps makes the case that the wellspring of this flourishing was modern values such as the desire to create, explore, and meet challenges. Most innovation wasn't driven by a few isolated visionaries like Henry Ford; rather, it was driven by millions of people empowered to think of, develop, and market innumerable new products and processes, and improvements to existing ones.

The analysis is clear in that one cannot imply that economic growth is a simple matter of investing in education. But it is also clear that significant and continuous investment in education over time lead to higher levels of technology and productivity, facilitating economic growth and higher standard of living. However, Goldin and Katz (2008) in their "race between education and technology" also show that the benefits from economic growth might be unequally distributed and a high average standard of living might not translate into betterment for all.

The implications of these remarks for Latin America are relevant, particularly to consider overall challenges of promoting capacity and quality of provision in a massified and diversified system of higher education. The US higher education system, among many others, can provide some insights. According to the Carnegie Foundation for the Advancement of Teaching, the few hundred "research universities" operate within a system of about 6,500 higher education institutions, including those providing vocational training. This diversity - and functional stratification of the system as a whole - helps responding to rapid changes in the employment market, particularly through those institutions more oriented towards teaching and with shorter graduation times, without putting undue pressure on research universities (Locke and Wellhausen, 20I4). It definite $y$ requires the building up of time-dependent and mature ecosystems, including intermediary institutions, as well as a great attention of the advanced qualification of skilled people and teaching staff for the entire education system and its links with the economy and the entire society. This is a continuous process, evolving a long-time framework. From an institutional perspective, the establishment of Graduate Schools is a possibility to foster the advanced training of human resources and the training of teaching staff. Graduate Schools have been developed worldwide over the past decade in diversified ways that range from interdisciplinary structures and based in a single university, to subject-specific inter-university structures. In general they provide a better link between research training and research environments and provide flexible postgraduate learning structures that traditional university departments cannot. Also, Graduate Schools could further develop current postgraduate activities contributing decisively to training programs for teachers and researchers, while at the same time enhancing the research capacity and knowledge base of all higher education institutions involved. 
This is of fundamental importance for most regions and countries in Latin America, where the number of students enrolled in graduate education, and particularly in $\mathrm{PhD}$ programs, is still rather limited when compared internationally, even in comparison with emerging countries in Asia. With the notable exception of the Universidade de São Paulo and the Universidade Estadual de Campinas in Brazil, most leading universities across Latin America still rely in undergraduate education, with the fraction of graduate students accounting for less that $20 \%$ of the overall number of students, Figure 6.
The analysis is particularly relevant when considering doctoral education and Figure 7 suggests a significant need for change and evolution in Latin American countries. Brazil, for example, has doubled the graduation of PhDs over the last decade, but still graduates only about 0.6 new PhDs per 10.000 inhabitants, when all European countries graduate above I.5, with Germany and the United Kingdom graduating more that 3.2 new PhDs per 10.000 inhabitants. For comparison, the highest PhD graduation levels are in Switzerland and in the North American State of Massachusetts, with levels above 3.5 new PhDs per 10.000 inhabitants.

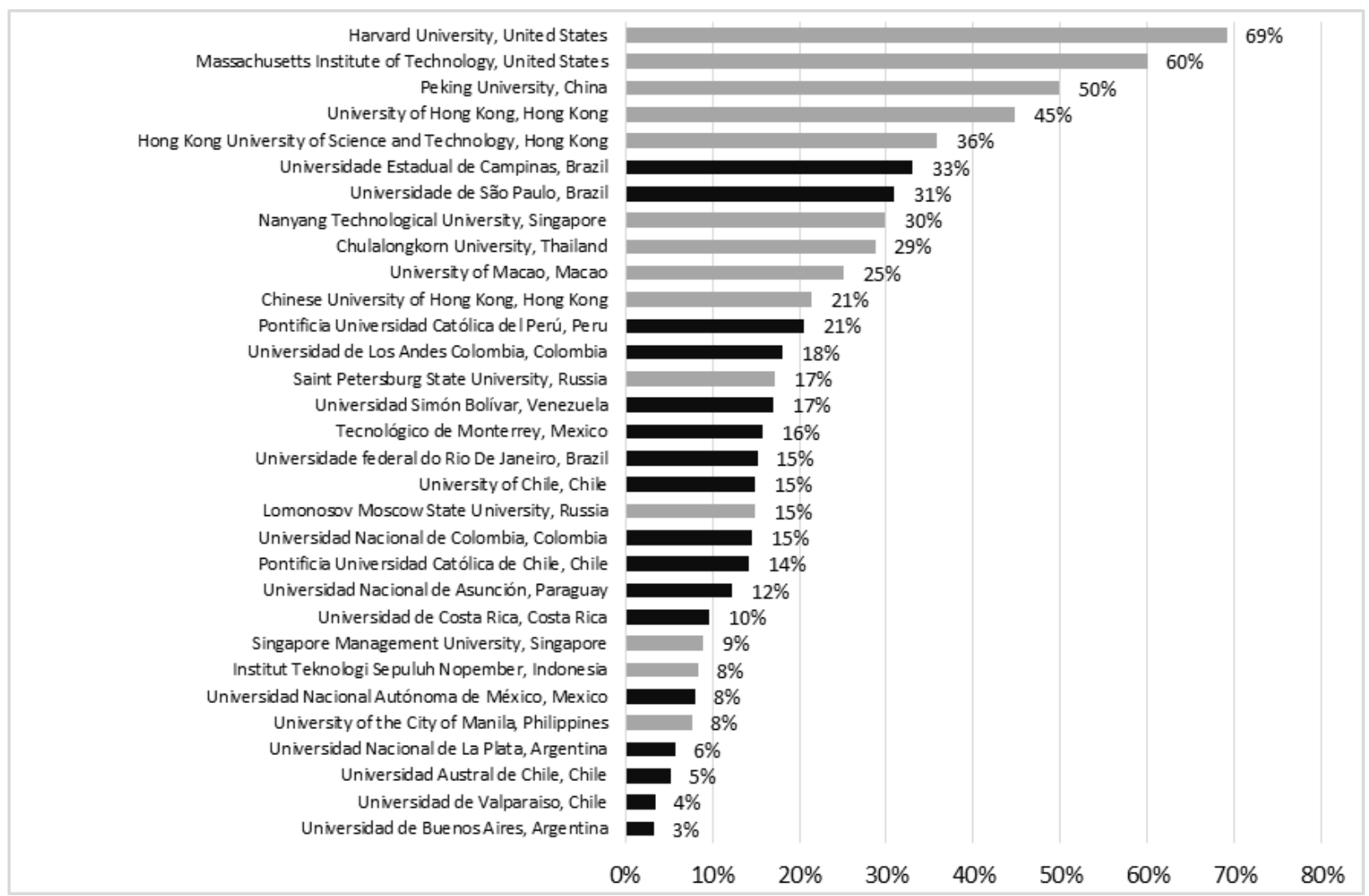

Figure 6 - Percentage of students enrolled in MSc and PhD programs in relation to the total number of enrollments in a sample od selected universities, for 201 I or last available year; Source: websites of universities

ISSN: 07 I8-2724. (http://www.jotmi.org) 
Doctoral education remains the most significant form to promote the advanced education of people and to build reliable universities, able to face emerging challenges in technical change. Beyond its fundamental role to differentiate universities in a diversified education system, it allows to strengthen the top of the knowledge pyramid by challenging institutions to approach leading edges of common knowledge and facilitate the production of new knowledge. It does not necessarily contribute for economic growth in a short-time framework, but represent a critical dimension in the long process of "university-science" relationships that allow fostering "industry-science" relationships. Doctoral education is also a fundamental step in developing national strategies for capacity building of the entire education system, with emphasis on training teachers and researchers for modern societies.
It is well known that higher education institutions can play a critical role in the process of training a qualified labour force while contributing decisively to related knowledge production and dissemination processes (Caree et al, 20l4). Their role is particularly relevant for establishing innovation communities, requiring a continuously qualifying teaching and research staff able to systematically train new generations of students and develop routines of collaboration on the basis of formal education programs, sophisticated research projects, and a diversified and non-structured array of informal processes of networking (Freitas et al., 2013).

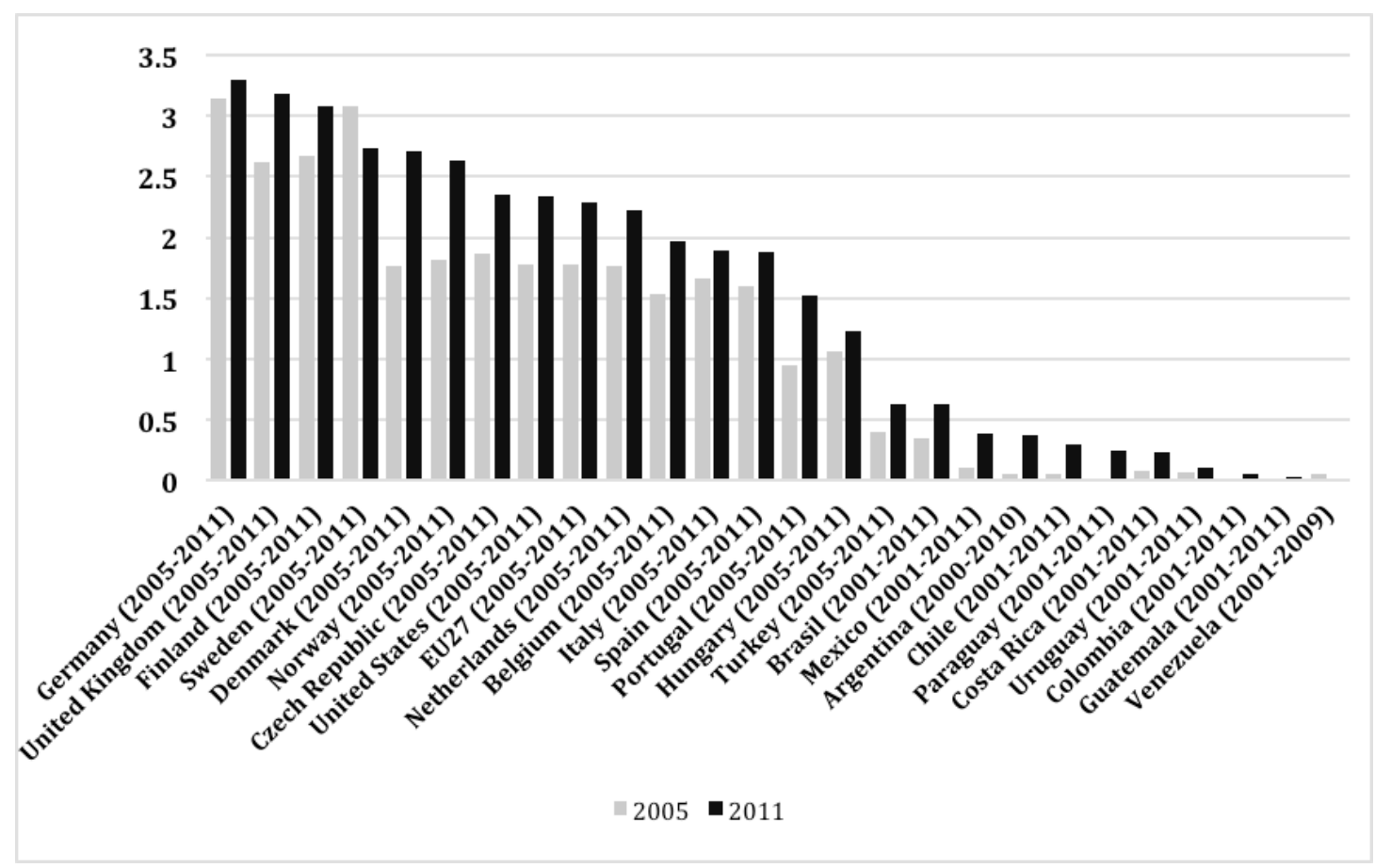

Figure 7. New PhDs per 10.000 inhabitants (2000/200I/2005 and 2009/20I0/20I I); Source: RICYT, EuroStat, OECD. 
The implications of our analysis for "university-science" relationships are straightforward. Doctoral education is closely linked to the production of new knowledge and requires the development of adequate learning environments that can only be provided by research-driven institutional frameworks.Academic research centres, developed together with Graduate Schools in modern universities, have shown to provide such type of environments across all disciplines for research-driven doctoral and post-doctoral education. The main issue is that they require a long-term vision in providing the necessary investment in science to facilitate the conditions to nurture knowledge intensive environments where researchers and academics can be trained (Zoller et al., 20l4).
The long-term commitment to investment in research and development is necessary since new knowledge results from cumulative processes, together with learning routines able to contribute to the necessary continuous update of research and teaching practices that need to keep up with a fast changing global and knowledge markets (Zeigler, 2012). Figure 8 quantifies the cumulative gross domestic expenditure on R\&D for the first decade of this century (i.e., 2000-2010) for a sample of selected countries and show very low relative levels for Latin America, when compared internationally. For example, the accumulation of investment in R\&D in Brazil over the decade under analysis was half of that in Korea, 3 times smaller than that in Germany and about 3.6 times smaller than that in China. We argue that these very low levels of investment in R\&D are not contributing to foster adequate advanced training levels of skilled people and are lagging behind modern values to foster the desire to create, explore, and meet emerging challenges.

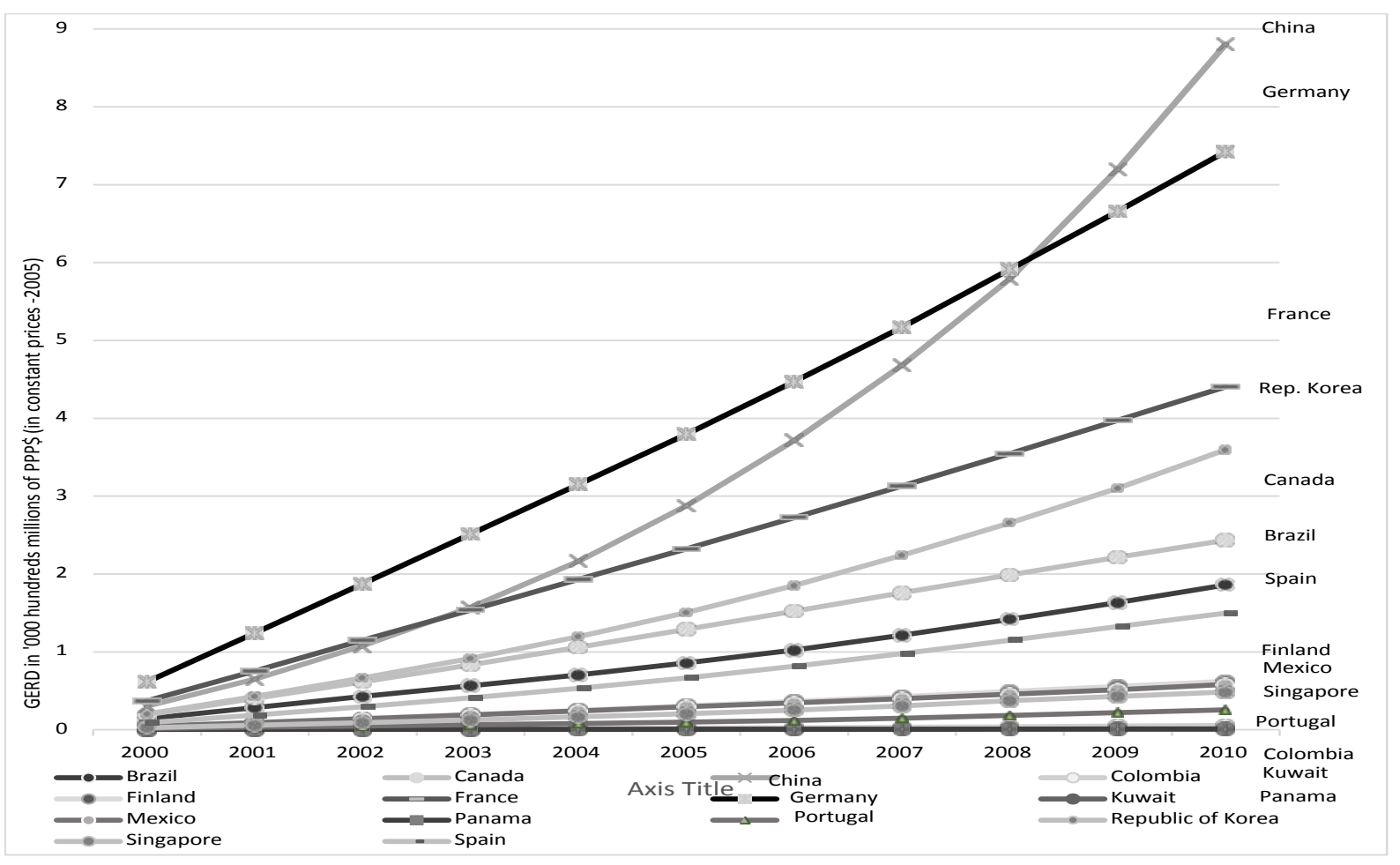

Figure 8 - Cumulative Gross Domestic Expenditure on R\&D between 2000 and 2010 (GERD in '000 PPP\$ in constant prices 2005) in selected countries; Source: UNESCO, OECD. 


\section{Discussion and policy implications: Promoting access and qualifications in Latin America}

It has become a common place to refer human capital as critical condition for the creation and dissemination of knowledge, in a way that striving towards greater human capital is of the utmost importance for any world region. This ultimate goal requires, per si, policies towards the renovation of higher education institutions, as well as for the expansion of the social basis for scientific and technological development and the appropriation of a scientific and technological culture (Majewski, 20/3). This underlines the need to further open-up access to higher education through various forms that take into account the experiences of people and non-linear life paths (Saar et al., 2014).

In addition, our analysis has shown the success of such policies imply effective institutional autonomy and integrity of modern higher education institutions in a context where innovation must be considered together with competence building and advanced training of people through the complex interactions between formal and informal qualifications (Helpman 2004). This requires broadening the social basis for knowledge activities and strengthening the top of the research system leading to knowledge production at the highest level. Figure 9 shows schematically our main argument, which is discussed in the following paragraphs.

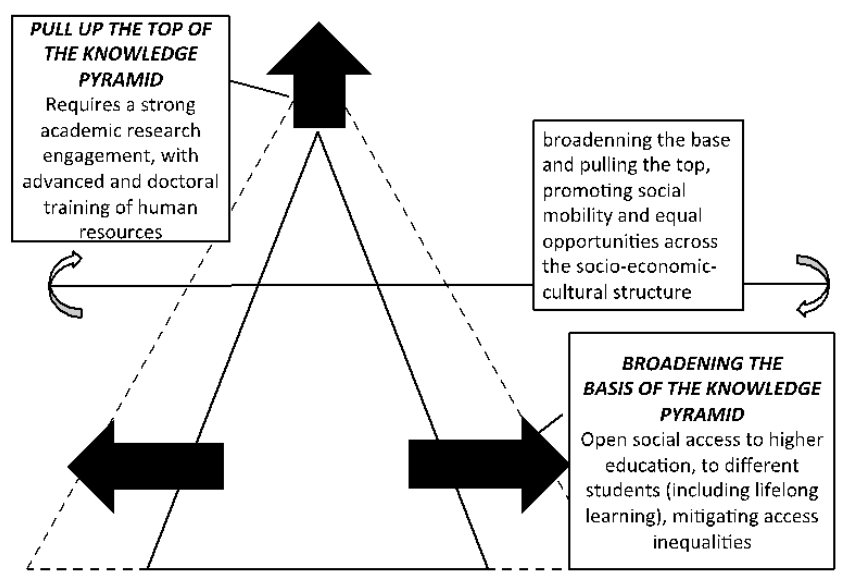

Figure 9 - Schematic representation of proposed "orthogonal" policies to foster access and qualification reducing scientific and kn wledge gaps

\section{On policies to broaden the basis for knowledge, promoting access to knowledge and learning}

The main reason for governments to increase funding for higher education is to increase participation rates and extend the recruitment base (Barr, 2004; Barr and Crawford, 2005). At the same time, new opportunities are required to give students more flexible pathways across different types and levels of educational qualification including through recognition of prior learning and credit transfer, in order to reduce repetition of learning. This can benefit from diversified higher education systems

Still, a key issue in Latin America is the need to open-up higher education by strengthening the "bottom of the pyramid" of Figure 9. We address this issue in two different, but related levels: i) operationally, looking at the process of attracting and funding students; and ii) strategically, looking at society, in general, and the process of gaining societal trust through a vigorous relationship between universities and the remaining education system.

First, our underlined assumption is that "students matter" and, as a result, increased diversified systems are required, as discussed in the previous section of this paper. But the need to modernise funding mechanisms and ensure a better balance between institutional and competitive funding for higher education is leading the discussion in governments worldwide. It appears that more important than discussing the details of funding formulas for institutional funding mechanisms, it is to review the overall share of institutional and competitive funding sources, as well as to promote student support mechanisms. This certainly includes the need to create flexible financial mechanisms to attract and secure people in academia.

The key issue is how to increase and balance loans and grants for students, as well as to develop innovative loan systems and to combine them with flexible legislation to accommodate reasonable student incomes through part time work. Barr (2004) keeps remembering us that the goal is to provide free education to all students, by guaranteeing graduates to share the costs. The question is that the correct amount to be shared among the taxpayer and graduates, as well as other private sources, is still to be shown (at least using scientific $g$ ounds).

Although income-contingent loan systems are becoming a typical reference worldwide, as acknowledged by the OECD, it should be noted that their applicability is particularly dependent on the characteristic of the existing fiscal system and very much inadequate for most developing and emerging regions worldwide, including Latin America. This is why an innovative system of student loans with mutual

ISSN: 07 I8-2724. (http://www.jotmi.org)

Journal of Technology Management \& Innovation (c) Universidad Alberto Hurtado, Facultad de Economía y Negocios. 
guarantee underwritten by the State was introduced in Portugal to complement the traditional system of public grants, as part of the Portuguese higher education reform in 2006-2010, thereby improving access to higher education for all students (Heitor et al, 20l4). Michael Gallagher, on a personal comment stated that "the Portuguese initiative satisfies the key policy criteria: it is a horizontally equitable scheme; it represents good value for students; it is financial y sustainable at higher volumes of student take-up; it is low risk for government and financial institutions; it avoids the need for additional administrative infrastructure. The loan facility reduces disincentives to study by covering reasonable living costs while deferring repayment obligations till after graduation. The allowable repayment period (twice the period of study) is normally sufficient to permit students to make loan repayments without committing a disproportionate share of their income after graduation".

Still regarding the Portuguese Loan System, Nicholas Barr, also on a personal comment, has recently "applaud the facts that: I) the scheme is universal; 2) supplements existing grants rather than replacing them, hence extends students' options; 3) has no blanket interest subsidy; 4) has a very innovative mutuality element, which is the key that makes it possible for the scheme; 5 ) to make use of private finance" The loans scheme also has incidental benefits by virtue of the progression requirements and the incentives for improving grade point averages. In particular, it has the potential to encourage students to progress and complete their studies, and it may encourage students to undertake courses that are more likely to lead to positive employment outcomes.

Our second level of analysis is associated with the need to strengthen external societal links as critical steps in fostering the role of higher education in society and to meet the needs of global competition and the knowledge economy. This issue has been discussed in US and Europe over the last fi e decades, either in terms of renewing science education, or creating science culture, and here we reinforce this argument with a specific pplication to Latin America.

The need is to foster the public understanding of science, as well as to better explain to society the role of universities on scientific and technical development. In this regard, Miller et al., (2002) acknowledges the leading role of national programs such as the "La Main a la Pate" in France, or the "Ciência Viva" in Portugal, but also recognize the still difficult climate for promoting science (and knowledge...) culture. The continued implementation of actions fostering "science for all" is a practice to follow, where the concept of "Knowledge integrated communities" appears particularly suitable to facilitate the joint enrolment of researchers, universities and basic and secondary schools in specific projects driving society at large. It is clear that this requires new knowledge about social behaviors, as well as new methodological developments to help moving emerging regions worldwide towards a knowledge society in a fast moving landscape. The objective is to integrate systems of knowledge and ways of practicing, where schools interact with universities in systematic ways, building routines of cooperative work.

In this context it is also important to note that understanding the relationship between higher education, the social contexts, and the public policy dialogue to include a modern rational considering the broad value of "research and learning", remains a significant challenge worldwide. This debate requires higher education institutions to better understand "how people learn". It is clear that learning systems vary considerably across the full spectrum of disciplines, but if the ultimate goal is to enlarge participation rates and the recruitment base of higher education, the debate will gain from current knowledge of basic and secondary education levels. Given the many changes in student populations, technology resources, and society's demands, new pedagogical approaches that are more student-centred and more culturally sensitive are needed.

The potential revolution for learning that the "networked world" provides is the ability to create scalable environments for learning that engages the tacit and the explicit dimensions of knowledge. The term that Brown and Douglas (2010) has used for this, borrowed from Polanyi, is "indwelling". Understanding this notion requires to connect experience, embodiment, and learning. First, the world of the 2 I st century is characterized by a sense of constant change, which requires to further rethink the notions of interaction with new knowledge towards a deeper understanding of participation (knowing). Second, the notion of experience (and participation) within new media contexts has shifted from a traditional sense of experiencing content to using content as context to construct a social world with others (making). Third, understanding the means by which networked media supports a kind of play (playing) that allows people to navigate the complexities of a constantly shifting world. What may be most important to understand is that each of these dimensions of learning is in the process of evolving in response to the demands of the 2 Ist century. In our emerging societies, knowing, making, and playing emerge as critical components of "becoming". In relation to this, the training of a teaching body through "universityscience" relationships can be highly beneficial 


\section{On the role of science policy to pull-up qualifications}

Let us turn now to the issue of reinforcing the top of education systems in Latin America by science policies able to attract and train a quality teaching body and fostering the specialization of universities. The key issue is the creation of the conditions able to strengthen institutions and to form the necessary critical masses to help facilitating high quality research activities.

In this respect, and following some of the issues initially raised by Ziman (1968) and, later, by Ernst (2003), one critically important and emerging institutional issue refers to the training of doctoral students and young scientists in order to provide them with core competencies that help them to become successful researchers and prepare them with the adequate "transferable skills" for the job market outside research and academia. The issue can be further oriented in three different lines of discussion.
First, this requires the adequate public funding to train and attract skilled people and a teaching body, making use of proper research environments, at home and abroad. It must consider the concentration of funds to spur forms of international academic and scientific cooperation oriented towards the research training of young scientists and future teachers. Increasing the investment in science and technology in Latin America is becoming critical to facilitate the conditions to nurture knowledge intensive environments where researchers and academics can be trained and develop knowledge based activities. Figure 10 complements the analysis of the previous section and shows that the gross expenditure on R\&D per capita in any Latin America country is still well below any acceptable value at an international level. In addition, it has not increased over the last decade at the level of the most industrialized countries. For example, after correcting for parity and at constant prices of 2005, the annual per capita expenditure in R\&D in Brazil is about 8 times smaller than that in Germany and one tenth of that in North America. Although it should be noted that it has notably increased about $50 \%$ over the period $2000-2011$, the related increase in Germany was about $67 \%$ and about $37 \%$ in North America. These figu es clearly show a long gap in the way Brazilian (and, in general, Latin America) society considers the investment in R\&D as matter of priority.

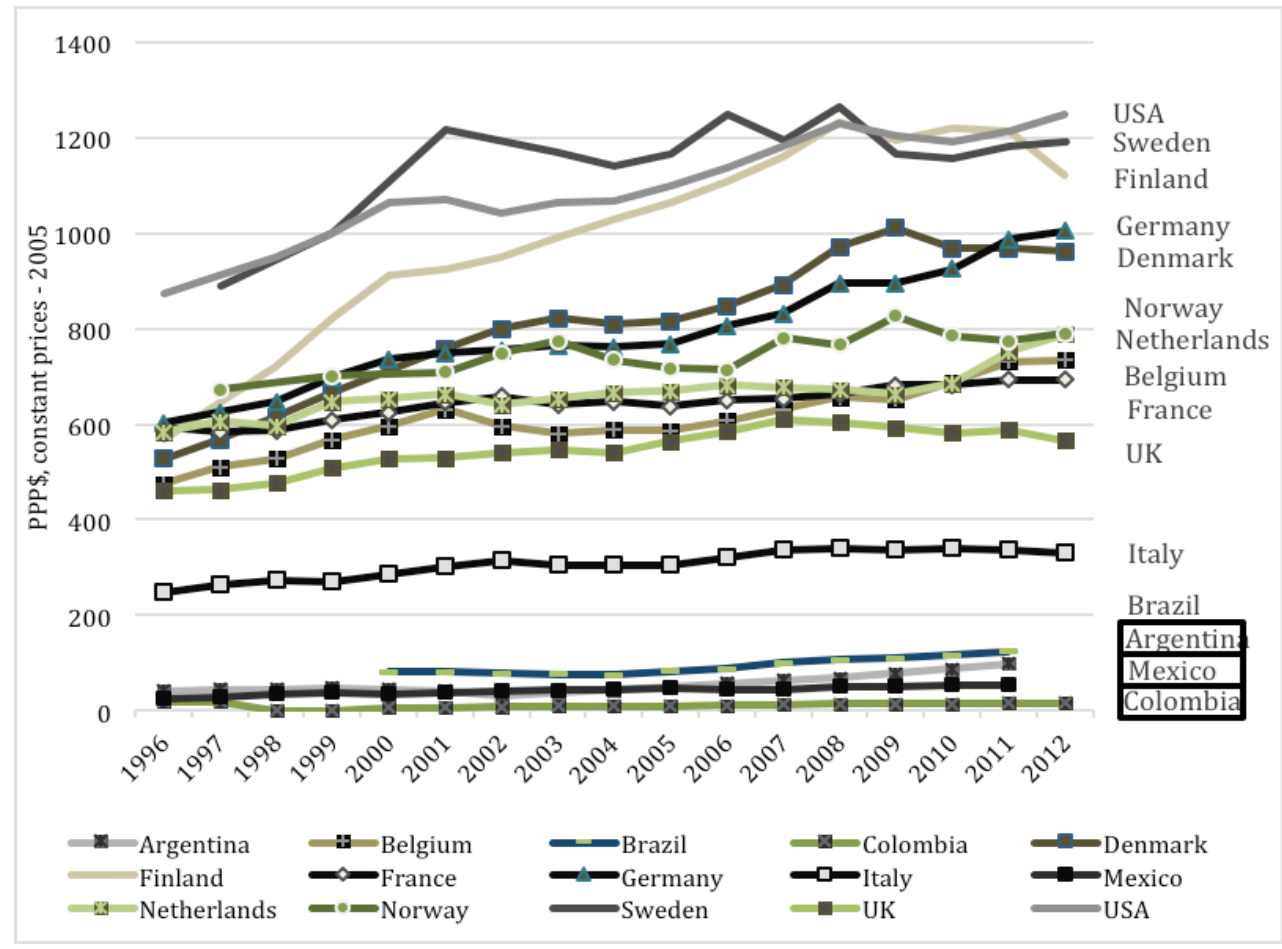

Figure 10. GERD per capita (in PPP\$, constant prices - 2005). Source: UNESCO Institute for Statistics

ISSN: 07 I8-2724. (http://www.jotmi.org) 
Second, at the institutional level, attracting skilled people and teaching staff to modernize and strengthen research universities has been particularly facilitated by establishing Graduate Schools, which have been developed progressively worldwide over the past decade, as discussed before in this paper. Our research also shows that international academic and scientific cooperation seems to emerge as a major shaping factor for development at an unprecedented level to address these issues (Heitor, 2014). It is well known that academic institutions from developed countries are now operating internationally, addressing not only potential students individually (this was the traditional paradigm), but increasingly developing new types of institutional arrangements, such as "international graduate schools". These should be considered a major goal for Latin America if developed in an "inclusive way" and further develop current postgraduate activities in many existing universities. We refer to foster effective international-wide training, helping monitoring or evaluating emerging institutions in most Latin America countries, transferring organizational skills, operating training programs for teachers and researchers, contributing to research capacity in a trans-national path and to the marketing of its benefits for economic and social progress in developing societies.

Third, it should also be noted that the debate has confirmed that the progress of scientific and technological knowledge is a cumulative process, depending in the long-run on the widespread disclosure of new findings For example, David (2007) has systematically shown that "open science is properly regarded as uniquely well suited to the goal of maximizing the rate of growth of the stock of reliable knowledge". As a result, universities should behave as "open science" institutions and provide an alternative to the intellectual property approach to dealing with difficult problems in the allocation of resources for the production and distribution of information. Consequently, the main challenge for public policies is to keep the proper balance between open science and commercially oriented R\&D based upon proprietary information.

In this discussion it should be made clear that in allocating public funding for higher education and the promotion of institutional diversification (Conceição et al., 2003), it is important to separate real resources from monetary resources and to explain their relationship with other factors relevant to the operation of higher education institutions. The traditional approach in many regions worldwide is that resources (faculty, administrative staff, students, R\&D projects) and the higher education institutions' facilities directly generate income. The latter, in turn, must be spent on maintaining the resources. In fact, in many funding systems, resources are the only element considered in determining public core funding, the logic of determining income being limited to supporting resources.
An alternative model was developed in the framework of a "context-input-process-output-outcome" system where the university financial $\mathrm{fl}$ ws should explicitly deal with activities and results, as well as resources and infrastructure (Conceição and Heitor, 2005). This model of the university's operation presents the idea of the institution as a "knowledge productive system", that is, resources and infrastructure (inputs) are used in activities, producing results (outputs). But these results in turn will generate income that finances activities, which as they unfold entail expenditure in order to support resources. This second part of the cycle represents the financial $\mathrm{fl}$ ws associated with the operation of the university. The model itself is based on the conceptualization of the higher education institutions' relationship with society and on the modeling of their operation, highlighting the existence of intangible $\mathrm{fl}$ ws as well as the tangible $\mathrm{fl}$ ws identified with teaching and esearch.

A critical argument is to acknowledge the university as an autonomous institution that creates knowledge and promotes creativity, supported by public funding policies. Horta et al (2008) suggest the use of science policy instruments based on research funding related mechanisms as a major policy instrument to diversify higher education. There are several benefits to use such competitive funding strategy. One of these benefits relates to the competitive nature associated with a well-consolidated evaluation framework.

Research evaluation practices tend to follow three important conditions, and it needs to be set apart from teaching (see Jauch, 1976). The first is the use of international expertise in research evaluation processes, a lesson learned from the Portuguese experience since the mid 1990s, where it played an important driving mechanism for the evolution of the entire research and academic system (Horta, 20l0). The second is that research assessments should not be based solely on quantitative indicators. Although quantitative evaluations may complement peer-review practices in view of the recognised criticisms of 'pure' peer-review assessments (Relman, 1990), the "extreme" quantification of the academic activity may impose a culture of "bureaucratization of knowledge". The third is that the evaluation process should be articulated with a continuous and periodic opening of competitive calls for research grants and fellowships that ought to take into account the missions of higher education institutions in order to foster institutional differentiation (see Conceição and Heitor, 2005).

The other benefit of a competitive funding strategy is that the allocation of such funding it is not so strongly impacted by positional goods as it is with respect to education (particularly at undergraduate level). Funding for the education component of higher education in Latin America should be mostly noncompetitive to support 
the development of learning infrastructures and activities. Even when competition exists in the education market, promoting diversity exclusively on that basis is relatively ineffective (Tavares and Cardoso, 2013). This occurs because of lacking relevant information for students and also because of the powerful impact of positional goods, which model students' choices. In addition, whereas research evaluation is a well-consolidated assessment, it is still difficult to measure and evaluate teaching performance (Dixit, 1998). Although certain authors defend the robustness of teaching evaluation processes such as student ratings (Marsh, 2007), academics and higher education administrators continue to express doubts about their meaningfulness and suitability (Gilliot, 200I).

\section{Challenging the institutional context: strengthening and promoting institutional autonomy}

We conclude our discussion with a special remark regarding the need to grant effective autonomy and independent legal status to higher education institutions in Latin America, in a way to give them the necessary capacity to self-govern and function in pursuit of work that is deemed essential to society (see Estermann et al., 20II). Among many others, Hasan (2007) identified the relevance of strengthening the regulatory regime to facilitate more autonomous institutions in line with the requirements of public interest. This is a "context-specific" matter and should be discussed as a function of the level of state bureaucracy, which is to be avoided in managing knowledge-based institutions.

At an operational level, the attribution of independent legal status through "foundations" has become a common practice in Europe in a way to promote public institutions governed by private law, of which Hasan (2007) identified four conditions for a successful implementation. First, accepting the foundation status should be voluntary. Second, because not all higher education institutions are either willing or capable of taking up the foundation option, the process should be planned on a case-by-case basis. Third, the level of autonomy granted has to be meaningful and based on a carefully decided strategic research and academic agenda. Fourth, the transition to a foundation status requires many support structures and arrangements, as well as, a professional management structure.

In this context, new legal regimes of higher education are required in most LatinAmerica countries to establish modern organizational principles, the autonomy and accountability of institutions, setting up governing boards with external participation, establishing consortia, and recognizing research centers as part of university management frameworks. This requires a package of reforms addressing various aspects of higher education autonomy. In particular, attention needs to be paid to ensuring that higher levels of autonomy are appropriately monitored so that they are put into the service of public interest.

\section{Summary}

The growing demand for education and the prospects for its rapid evolution in many Latin American countries in the years to come is calling for the need to better integrate science and education policies in a way to further democratizing and promoting socio-economic development through two complementary goals: i) opening access to the knowledge base through higher education; and ii) promoting advanced qualification of skilled people and strengthening research institutions through adequate consideration of human resources and institutional issues in the process of technical change. We argue this requires a better understanding of diversity in higher education, together with further democratizing access in general, and making it more socially balanced.

To cope with such a variety of demands and with a continuously changing environment, this paper argues that higher education institutions should continue to promote the necessary institutional integrity to facilitate students to experience environments of free knowledge production and diffusion (Conceição et al., 2006). In internal organizational terms, this requires adaptable and resilient institutions. In public policy terms, by focusing governmental activity on human resources and on strengthening institutional autonomy, we require political actions to concentrate on critical pillars of democracy.

In other words, by focusing public policies on the "external" dimensions of knowledge institutions through attracting people and foster opportunities for knowledge production, governments and major pubic and private stakeholders are imposing higher education institutions to strengthen their capacity to make the critical internal changes for building and modernising their systems of teaching and research within a path of diversity and specialisation, without compromising quality. Furthermore, by strengthening their institutional integrity together with enhancing their external links with society, higher education institutions are asked to carefully improve their relationships with economic, social and political actors, thereby creating "new" reinforced institutions that have gained societal trust.

Our research across Latin America in the last three years suggests that this requires broadening the social basis for knowledge activities and strengthening the top of the research system leading to knowledge production at the highest level. It definite $y$ requires a great attention of the advanced qualification of skilled people and teaching staff for 
the entire education system and its links with the economy and the entire society. This is a continuous process, evolving a long-time framework, requiring a proper understanding of the effective role played by science-university relationships, beyond the most "common places" and currently dominating policies of thinking science through short-term, demanddriven economic development issues. Our final observation is that effective institutional autonomy of higher education institutions and diversity of higher education systems are to be promoted in a context where building human capital is a priority for Latin America.

\section{References}

ALTBACH, Phillip, Liz Reisberg, Laura E. Rumbley (2009), "Trends in Global Higher Education: Tracking an Academic Revolution”, Paris: UNESCO

BATTELLE (2013), "2014 Global R\&D Funding Forecast"; December 2013, www.battelle.org

BARR, N. (2004), Higher Education Funding. Oxford Review of Economic Policy, 20, 2, pp. 264-283.

BARR, N. and Crawford, I. (2005), "Financing Higher Education: answers from the UK”, London: Routledge.

BIJKER, WIEBE E., Thomas P. Hughes, and Trevor Pinch (1987), "The social construction of technological systems", Cambridge: MIT Press.

BOLIVER, V. (20II), Expansion, differentiation, and the persistence of social class inequalities in British higher education. Higher Education, 6I, 3, 229-242.

BROWN, J. S. and Douglas, T. (2010), "A New Culture of Learning: Cultivating the Imagination for a World of Constant Change", CreateSpace 20II.

CARLSON, B. (2002), Education and the labor market in Latin America: confronting globalization. CEPAL Review, 77, II7-I34.

CARREE, M.,Malva,A.D.,Santarelli,E.(20I4),The contribution of universities to growth: empirical evidence from Italy. The Journal of Technology Transfer, 39, 3, 393-4I4.

CONCEIÇÃO, P., and Heitor, M.V. (2002), Knowledge Interaction Towards Inclusive Learning - Promoting Systems of Innovation and Competence Building, Technological Forecasting and Social Change. 69, 7, pp. 64I-65I.

CONCEIÇÃO, P. and Heitor, M.V. (2005), “Innovation for All? Learning from the Portuguese path to technical change and the dynamics of innovation", London: Praeger.

CONCEIÇÃO, P., Heitor, M.V., and Veloso, F. (2003), Infrastructures, Incentives and Institutions: Fostering Distributed Knowledge Bases for the Learning Society. Technological Forecasting and Social Change, 70, 7, pp. 583617.

DAVID, P. (2007), “The historical origin of 'open science' An Essay on Patronage, Reputation and Common Agency Contracting in the Scientific Revolution", Stanford: Stanford Institute for Economic Policy Research. 
DIXIT, A. K. (1998), "The making of economic policy: A transition-cost politics perspective - Munich lectures in economics", Cambridge: MIT Press.

ERNST, D. and Kim, L. (2002), Global production networks, knowledge diffusion, and local capability formation. Research Policy, 31, 8-9, pp. |4|7-| 429.

ERNST, R. R. (2003), The Responsibility of Scientists, a European View. Angewandte Chemie International Edition, 42, pp. $4434-4439$.

ESTERMANN,T., Nokkala,T. and Steinel, M. (20I I), University Autonomy in Europe II, Brussels: European University Association.

FREITAS, I.M.B., Marques, R.A., and Silva, E.M.P. (20I3), University-industry collaboration and innovation in emergent and mature industries in new industrialized countries. Research Policy, 42, 2, 443-453.

GILLIOT, D. (200I), Incentives in academia, In Dewatripont Mathias, Thys-Clemenat, Françoise, and Wilkin, Luc, "The Strategic Analysis of Universities: Microeconomic and Management Perspectives", Brussels, Editions de L' Université de Bruxelles, pp. 57-7I.

GIORDANO,A., and Pagano,A. (20I3), Brazil in the transition towards knowledge economy: between qualification and internationalization of human capital. Transition Studies Review, 20, I, 19-3I.

GOLDIN, C.D. and Katz, L.F. (2008), The Race between Education and Technology, Harvard University Press, 2008

JAUCH, L.R. (1976), Relationships of research and teaching: implications for faculty evaluation. Research in Higher Education, 5, I, I-I3.

KOLJATIC, M., and Silva, M. (20I3), Opening a side-gate: engaging the excluded in Chilean higher education through test-blind admission. Studies in Higher Education, 38, 10 , |427-|44|.

KOHLI, A. (2009), Nationalist versus dependente capitalista development: alternate pathways of Asia and Latin America in a globalized world. Studies in Comparative International Development, 44, 4, 386-4I0.

HASAN, A. (2007), Independent legal status and universities as foundations, Lisbon: Portuguese Ministry of Science, Technology and Higher Education.
HEITOR, M. V. (2008), A system approach to tertiary education institutions: towards knowledge networks and enhanced societal trust. Science and Public Policy, 35, 8, pp. 607-6I7.

HEITOR, M.V. (20I4), How far university global partnerships may facilitate a new era of international affairs and foster political and economic relations?, Technological Forecasting and Social Change, accepted to publication.

HEITOR, M. V., and Bravo, M. (2010), Portugal on the crosstalk of change, facing the shock of the new: People, knowledge and ideas fostering the social fabric to facilitate the concentration of knowledge integrated communities. Technological Forecasting and Social Change, 77, pp. 218-247.

HEITOR , M, Horta, H. and Leocádio, M. (20l4), Student loans with mutual guarantee: $A$ new risk-sharing scheme to foster student access and autonomy in higher education, Technological Forecasting and Social Change, accepted to publication.

HELPMAN, E. (2004), "The mystery of economic growth". Cambridge: Harvard University Press.

HORTA, H., Huisman, J. and Heitor, M.V. (2008), Does a competitive research funding encourage diversity in higher education? Science and Public Policy, 35, 3, pp. I46-I58.

HORTA, H. (20I0), The role of the state in the internationalization of universities in catching-up countries: An analysis of the Portuguese higher education system. Higher Education Policy, 23, pp. 63-8I.

LALL, S. (1990), "Building Industrial Competitiveness in Developing Countries", Paris: OECD

LARSON, R.C., and Murray, M.E. (2008), Distance Learning as a tool for poverty reduction and economic development: a focus on China and Mexico. Journal of Science Education and Technology, 17, 2, I75-196.

LOCKE, R.M., and Wellhausen, R.L. (20/4), "Production in the innovation economy", Cambridge: MIT Press

MAJEWSKI, E. (20I3), Higher education reform: matching education to labour market needs. European View, 12, 2, 179-188.

MARSH, H. W. (2007), Students' evaluations of university teaching: A multidimensional perspective, In Raymond P. Perry and John C. Smart (Eds.), "The scholarship of teaching and learning in higher education:An evidence based perspective", New York: Springer, pp. 319-384 
MILLER, S., Caro, P., Koulaidis, V., Semir, V., Staveloz, W. and Vargas, R. (2002). Report from the Expert Group Benchmarking the promotion of RTD culture and Public Understanding of Science. http://www.jinnove.com/upload/ documentaire/PP-fe-I06.pdf

NOWOTNY, H., Scott, P. and Gibbons, M. (2003), Mode 2' Revisited: The New Production of Knowledge. Minerva, 4I, Pp. I79-194.

PHELPS, E.S. (20I3), "Mass flourishing How grassroots innovation created jobs, challenge, and change", Princeton University Press, 2013.

RELMAN, A. S. (1990), Peer review in scientific journalsWhat good is it? Western Journal of Medicine, 153, pp. 520522

ROBERTS, J. T. and Hite, Amy B. (2007), "The globalization and development reader: Perspectives on development and global change", Malden: Blackwell

SAAR, E., That, K., and Roosalu, T. (2014), "Institutional barriers for adults' participation in higher education in thirteen European countries". Higher Education. Online first

SAXENIAN, A. (2006), "The new Argonauts: regional advantage in a global economy", Cambridge: Harvard University Press.

TAVARES, O., and Cardoso, S. (2013), Enrolment choices in Portuguese higher education: do students behave as rational consumers?, Higher Education, 66, 3, 297-309.

TEICHLER, U. (2008), Diversification? Trends and explanations of the shape and size of higher education. Higher Education, 56, 3, 349-379.

TEIXEIRA, P.N., Rocha, V., Biscaia, R., and Cardoso, M.F. (20I2), Competition and diversity in higher education: an empirical approach to specialization patterns of Portuguese institutions. Higher Education, 63, 3, 337-352.

TROW, M. (2007), Reflections on the Transition from Elite to Mass to Universal Access: Forms and Phases of Higher Education in Modern Societies since WWII. In James J.F. Forest and Phillip G.Altbach (Eds), "International Handbook of Higher Education”, 18, (pp. 234-280).

TUNG, R. L. (2008), Brain circulation, diaspora, and international competitiveness. European Management Journal, 26, pp. 298-304.
WEFHORST, H.G. van de (20I4), Changing societies and four tasks of schooling: challenges for strongly differentiated educational systems. International Review of Education, 60, I, I23-I44.

ZEIGLER, D. (20I2), Evolution and the cumulative nature of science. Evolution Education and Outreach, 5, 4, 585-588.

Ziman, J. (1968), "Public Knowledge:The Social Dimension of Science", Cambridge: Cambridge University Press.

ZOLLER, F.A., Zimmerling, E., and Boutellier, R. (2014), Assessing the impact of the funding environment on researchers' risk aversion: the use of citation statistics. Higher Education, Online first 